\title{
UNDP DRC's Interventions for Sustaining Peace and Operationalisation of Humanitarian- Development-Peace Nexus in the DRC
}

United Nations Development Programme Democratic Republic of Congo (UNDP DRC Office)

\section{Contents}

I. Introduction

1. The DRC, a Country Facing Major Challenges of Peace and Development

2. The Need for a Coordinated Response from the International Community in Support of the DRC

II. New Deal for Engagement in Fragile States and Development Planning Process Initiated by the Country since 2001 to Address Issues of Peace and Development 1. New Deal Process for Engagement in Fragile States

2. Development Planning Process in the DRC in a Context of Fragility and Recurrent Conflicts

III. Interventions by UNDP DRC and Its Key Partners for Sustaining Peace in DRC

1. International Security and Stabilisation Support Strategy in Eastern DRC (I4S)

2. The Humanitarian Fund (OCHA)

3. UNDP's Interventions as Part of Its Programmatic Steering Wheel

IV. Operationalisation of the Nexus in the DRC: A Coordinated Approach to Interventions to Effectively Address Humanitarian, Development, and Peace Issues in Post-Conflict Areas in the DRC

1. Rational of an Integrated Approach to Nexus-based Interventions in Post-Conflict Areas

2. Approach and Methods of Operationalisation of the Nexus

3. Operationalisation of the Nexus in the Context of DRC

4. Implementation Phasing of the Nexus in an Identified Nexus Driver Would Then Decline

5. Nexus Pilots Identified in the DRC

6. Axes of Possible Thematic Interventions of the Nexus

7. UNDP Strategic Positioning in the Nexus

V. Opportunities and Recommendations for a Strengthened Partnership with Donors, Mainly Bilateral Donors, Including KOICA, for 'Sustaining Peace' in the DRC

VI. Conclusion

References 


\section{Abstract}

The humanitarian response has brought much relief to the plight and suffering of the affected Congolese people. However, despite significant humanitarian interventions for the last two decades, the living conditions of the populations affected by the crises remain difficult. Thus, while recognising the achievements of humanitarian interventions, it has emerged the need for an integrated, inclusive and coordinated approach to gradually transform the dividends of humanitarian action into sustainable recovery, capacity for resilience and development opportunities. It is this imperative that responds to the Nexus, which is understood as a set of structured and coordinated interventions led by the actors involved in the Humanitarian, Development and Peace continuum, based on a joint multi-year program, which allow achieve sustainable collective results, with a low residual risk of falling back into the previous situation.

In this context, this note presents the United Nations Development Programme in the Democratic Republic of Congo's (UNDP DRC) interventions for Sustaining Peace and the operationalisation of Nexus with proposed Nexus pilots in the context of DRC. The first section presents how Development Planning Support including New Deal contributes to Sustaining Peace. The second analyses the interventions of UNDP and its partners. The third explores the operationalisation of the Nexus in the DRC and the latter notes the opportunities for partnership on the Nexus Pilots.

Keywords: Operationalisation of Humanitarian-Development-Peace Nexus, United Nations Development Programme (UNDP), Democratic Republic of Congo (DRC) 


\section{Introduction}

\section{The DRC, a Country Facing Major Challenges of Peace and Development}

Surrounded by nine bordering countries, the Democratic Republic of Congo (here in after referred as DRC) is a vast country in the heart of Africa that extends over an area of more than 2.3 million $\mathrm{km}^{2}$. It is the second largest country in Africa and the fourth most populous, with a population estimated at 77.3 million, of which $60 \%$ live in rural areas. Its population is characterised by a preponderance of women (53\%) and young people (60\%). It has significant natural resources1) but remains a poor and underdeveloped country in the rank of Least Developed Countries (LDCs) and low human development. At the end of its 2006 constitution in 2015, it is a decentralised state, made up of 26 provinces. Its (semi-presidential) political system is essentially democratic, with a separation of powers between the executive, the legislature and the judiciary. But its weak electoral system does not yet allow the country to lay the foundations for a modern and democratic state.

The DRC is a fragile country that is struggling to recover from a period of political, security and economic instability that has lasted for more than two decades with many Internally Displaced Persons (here in after referred to as IDPs) and massive human rights and serious crimes violations were committed. Despite the presence of approximately 100 armed groups in the country, particularly in the East, and the persistence of many remaining pockets of insecurity, which undermine peace and stability, several provinces and parts of the east are experiencing a positive dynamic of pacification, where the authority of the State, the justice and the reconciliation of the communities settle progressively, thanks to the support of United Nations Organization Stabilization Mission in the DRC (here in after referred to as MONUSCO in French acronym) and the partners of development, among which the United Nations Development Programme (here in after referred to as UNDP). The

1) The DRC is rich in important natural resources: $10 \%$ of the world's copper reserves, more than $50 \%$ of the world's cobalt reserves, $70 \%$ of the coltan reserves, $60 \%$ of the tropical forests, $37 \%$ of the world's hydropower potential, etc. 
overall context of the country, however, remains daunting in terms of humanitarian, security, peace and human rights, political and economic governance, and development.

On the humanitarian, security and peace front, since 2016, the humanitarian crisis, concentrated more in the East (North Kivu, South Kivu, Tanganyika, and Maniema), has spread to the centre of the country, particularly in the Grand Kasai region, affecting areas previously considered stable, and exhausting the adaptive capacity of those already affected. According to estimates by humanitarian actors, in 2017, the crisis plunged nearly 13.1 million people (including 7.7 million children) in need of humanitarian assistance and protection, nearly 14\% of the total population of the country. And nearly 4.3 million people are internally displaced (1.7 million in 2017 alone). The weakening of the authority of the State at all levels (central, provincial, and local), resulting from the delay in the implementation of major reforms in the sovereign sectors (defence, security, justice, police, provincial and local civil service), decentralisation has favoured the development of areas of lawlessness and the proliferation of armed groups and ethnic militias, which are torn apart in particular for the control of mining income and land, against the backdrop of poverty, the problem of identity and regional dynamics.

At the same time, through recurrent crises, malnutrition and severe food deficits have affected more than 12.8 million people in 2017 (WFP, 2017), and previously endemic diseases2) such as cholera, measles, measles, yellow fever, and Ebola disease resurface (WHO, 2017), mainly in the conflict-affected eastern and central provinces, thus increasing the vulnerability of populations.

2) According to the HRP 2017-2019 and the 2017 Health Ministry Sanitary Report, more than 50,000 cholera cases were recorded in 2017, including 1,070 deaths, an increase of 90.3\% over the same period of 2016, with nearly $70 \%$ of cases reported in the eastern DRC. Measles affected 41,778 cases in the same year, including 502 deaths. The majority of reported cases are also concentrated in the eastern provinces. Regarding yellow fever, the number of cases reported in 2017 (968 cases including 50 deaths) decreased compared to 2016 (3,283 cases including 50 deaths). Major risks of recrudescence remain in 2018, due to the deterioration of the conditions of access to water, and the hygiene and sanitation structures in the conflict and reception areas of displaced persons and refugees. The Ebola Virus Disease (EVD) arose in 2018 in Equateur province (30 deaths), the poorest province in the country, and in North Kivu province (already nearly 150 deaths), affected for three decades conflict. The latter is the 10th episode of the EVD pandemic since 1975. 
In terms of political governance, the DRC is currently engaged in a process of organising the presidential, legislative and provincial elections, in order to offer a more stable future to the Congolese people. The general elections scheduled for December 23, 2018 have reached a turning point with the appointment by the majority and the opposition of their presidential candidates. These elections raise great expectations both within the Congolese population and at the level of the international community, because they pose important issues in the perspective of consolidating the stability and peace of the DRC and the entire region. In addition, the overall situation of political and economic governance remains precarious, characterised in particular by a non-transparent management of public affairs in particular mining and forestry contracts - and impunity maintained by the weakness of the means of control and repression. The bank account suffers from several dysfunctions that limit its resources and its external control functions including jurisdictional. Similarly, the effectiveness of parliamentary institutions (national and provincial) remains limited in relation to their executive control role. Thus, despite the organisation of two general elections in 2006 and 2011, and the adoption of a new constitution in 2006, as modified and amended in 2011, the country still faces the challenges of building effective institutions, catering the authority of the state, the creation of an open political space and the participation of civil society and the media in public life. Beyond the worrying political, humanitarian and security situation, the socio-economic and human development context remains precarious and marked by poverty, mass unemployment, inequalities, and shortcomings in the provision of the main basic services (drinking water, health, and education), and the lack of economic opportunities for young people, that pushes them to turn to armed groups controlling the illegal exploitation of minerals. According to the latest statistics (National Statistics Institute of the DRC-UNDP, 2017), the social and economic conditions of the Congolese population remain very precarious and vulnerable. Nearly $63 \%$ of the population continue to live below the poverty line, with large disparities between cities (47\%) and rural areas (79\%). And the proportion of the population living in severe multidimensional poverty is increasing dramatically (48.5\% in 2017 against 36.7\% in 2015). High inequalities in both the distribution 
of Human Development Index (here in after referred to as HDI) earnings (the loss of human development due to inequality is estimated at 30.3\% in 2017) than in the income distribution (Gini index 0.39), continue to amplify. Similarly, the gap in human development between men (HDI 0.492) and women (HDI 0.420) continues to widen, reflected by the deterioration of the Gender Development Index (GDI), which rose to 0.852 in 2017 vs. 0.833 in 2016. On the other hand, the labour market remains narrow and characterised by strong inequalities towards young people, the vulnerable and women. The underemployment rate exceeds 50\%. And the employment structure remains dominated by the informal sector, which accounts for more than $88 \%$ of the total. These data reveal that the reduction of poverty and the improvement of the living conditions of Congolese people requires the establishment of a strong economic growth policy, coupled with a satisfactory redistributive policy.

On the other hand, many factors aggravating fragility - likely to undermine any prospect of development of the country in the medium and long term - continue to be perpetuated and strengthened, including uncontrolled urbanisation, deindustrialisation which drives the growth of the informal sector, demographic dynamics, and the proliferation of armed groups. Major structural reforms and pro-active policies are needed to stem these phenomena.

\section{The Need for a Coordinated Response from the International Community in Support of the DRC}

The humanitarian response has always been positive and has in many ways brought much relief to the plight and suffering of the affected Congolese people. However, despite significant humanitarian interventions undertaken by humanitarian actors for almost two decades and those initiated as part of the stabilisation of eastern DRC by MONUSCO, the living conditions of the populations affected by the crises remain difficult. The need to improve these conditions in a sustainable way and to transform conflict dynamics is imperative. Thus, while recognising the achievements of humanitarian interventions, it has emerged, through several studies 
and collective perceptions, the need for an integrated, inclusive, and coordinated approach to gradually transform the dividends of humanitarian action into sustainable recovery, capacity for resilience and development opportunities. It is this imperative that responds to the Nexus, which is understood as a set of structured and coordinated interventions led by the actors involved in the Humanitarian, Development and Peace continuum, based on a joint multi-year program, which allow achieve improved and sustainable collective results, with a low residual risk of falling back into the previous situation.

This note tries to develop this new Nexus approach in the context of the DRC. It is subdivided into four parts. The first presents the New Deal for engagement in fragile states and Development Planning Processes Engaged by the Country since 2001 to Address Peace and Development Issues; the second analyses the interventions of UNDP and its partners for a lasting peace in the DRC; the third section on the operationalisation of the Nexus as a coordinated approach to effectively addressing humanitarian, development, and peace issues in the DRC; and the latter notes the recommendations for the development of a strengthened partnership with donors, especially bilateral ones. 


\section{New Deal for Engagement in Fragile States and Development Planning Process Initiated by the Country since 2001, to Address Issues of Peace and Development}

\section{New Deal Process for Engagement in Fragile States}

The DRC is one of the self-declared fragile countries emerging from a protracted conflict that has destroyed almost all of its basic socio-economic infrastructure and weakened the institutions and authority of the state. Despite the positive evolution of political stability since the 2000s and the implementation of political and economic reforms by successive governments, the political legitimacy of the rulers remains disputed and the socio-economic and human development indicators remain weak. This situation highlights the fragility of the country and the need for the authorities to accelerate institutional, economic, and social reforms with a view to creating the necessary conditions for lasting peace and sustained growth and creating decent jobs. The New Deal process, international engagement for peacebuilding and statebuilding in fragile states, launched in 2011 at the 4th High Level Forum on Aid Effectiveness in Busan, South Korea, is an effective international instrument that addresses these issues of fragility. It provides strong upstream tools such as FOCUS3) and TRUST4) tailored for fragile and conflict-affect settings to step

3) FOCUS Principles are Country-led pathways out of fragility that the members of the International Dialogue on Peacebuilding and Statebuilding (here in after referred to as IDPS) agreed to FOCUS on new ways of engaging with conflict-affected and fragile states, including the following: Fragility Assessment, One Vision, One Plan, Compact, Use Peacebuilding and Statebuilding Goals to Monitor, Support political dialogue and leadership (IDPS, "New Deal Principles," available at https://www. pbsbdialogue.org/en/new-deal/new-deal-principles/ (accessed on November 25, 2018)).

4) TRUST Principles are Commitment for Results that the members of the International Dialogue agreed to build mutual TRUST by providing aid and managing resources more effectively, and by aligning these resources for better results. In doing so, they seek to increase transparency, risk management to use country systems, strengthen national capacities and timeliness of aid, improving the speed and predictability of funding to achieve better results. This includes the following: Transparency, Risk Sharing, Use and Strengthen Country Systems, Strengthen Capacities, Timely and Predictable Aid : (IDPS, “New Deal Principles," available at https://www.pbsbdialogue.org/en/new-deal/new-dealprinciples/ (accessed on November 25, 2018)). 
forward for peacebuilding and statebuilding.

The DRC has subscribed to the New Deal and launched, with the technical and financial support of UNDP, an ambitious roadmap, which has yielded encouraging results. In 2013 and 2016, fragility assessments of the New Deal's five Peacebuilding and Statebuilding Goals (here in after referred to as PSGs) containing specific actions, with monitoring indicators, were elaborated and adopted by all stakeholders at the national level (Government, sectoral partners, and Non-Governmental Organizations (here in after referred to as NGOs)). These PSGs and actions were integrated in 2017 into the National Strategic Development Plan (here in after referred to as PNSD in French acronym), for their effective implementation (One Vision and One Plan of the FOCUS tools of New Deal). In 2018, a comprehensive and detailed analysis of the five PSGs and the fragility spectrum of the DRC was re-conducted in 18 provinces out of total 26 provinces with a clear objective to capture the decentralised realities in a participatory manner which was not taken into account in the previous two assessments. As envisaged by the project, the project is supporting to make enabling-environment for coordination of all actors through Compact or Mutual Accountability Framework (the third component of the FOCUS tools), which is key for the operationalisation of the Nexus, amongst actors of government, donors, NGOs, universities, and private sectors across the humanitarian, development and peace agendas. For this process, a fragile-to-fragile peer-learning workshop between DRC and Sierra Leone with ten g7+ countries has been recently organised and the key actors of the DRC's New Deal from the government, civil society, universities and private sector have participated in the workshop and produced a Roadmap towards Compact for a concrete strategy for coordination such as creation of multi-actors dialogue platform and funding facility. These can, in turn, contribute to the operationalisation of Nexus.

\section{Development Planning Process in the DRC in a Context of Fragility and Recurrent Conflicts}

Since 2001, the DRC's development objectives and priorities across the three 
programmatic cycles have evolved but remain on a common foundation. Take the country out of its fragility by addressing the challenges of peace, poverty, governance, and employment. The first Interim Poverty Reduction Strategy Paper (PRSP) covering the period 2002-2005 aimed at stabilising and rebuilding the country after the years of conflict. The second Strategy Paper for Growth and Poverty Reduction 2006-2010 (GPRSP-1) aimed to improve governance and boost pro-poor growth. And the third MDG-based 2011-2015 Growth and Poverty Reduction Strategy Paper (GPRSP-2) aimed at boosting job-creating growth and reducing the impact of climate change.

Since 2015, the country has embarked on the participatory and inclusive process of developing the next national programme framework called the PNSD 2019-2014, which aims to unite all sectoral development strategies and policies. It aims to make the DRC a middle-income country in 2024 based on two levers: the development of mining potential and the transformation of agriculture. To organise this march towards the rank of middle-income countries, the Government plans to articulate its action around five strategic pillars: (i) strengthening governance and consolidating peace, democracy, and fundamental freedoms, to boost change and strengthen peace; (ii) consolidation of growth through economic diversification; development and modernisation of basic socio-economic infrastructure to support growth; (iii) social development and resource development, with a view to increasing socio-economic opportunities for all segments of the population; and (iv) balanced and sustainable development of all provinces and the fight against climate change. However, demographic dynamics, the infrastructure deficit, and the recurrence of armed and inter-communal conflicts could thwart this ambition. 


\section{Interventions by UNDP DRC and Its Partners for Sustaining Peace in DRC}

To address issues of peace and development in the DRC, UNDP and its partners "Humanitarian (OCHA) and Stabilisation (I4S)" are particularly active through three programmatic vehicles: the International Security and Stabilisation Support Strategy in the eastern DRC (here in after referred to as I4S), Humanitarian Fund (United Nations Office for the Coordination of Humanitarian Affairs, here in after referred to as OCHA), and UNDP programmatic steering wheel.

\section{International Security and Stabilisation Support Strategy in Eastern DRC (I4S)}

The I4S is an instrument of the United Nations (here in after referred as UN) and the international community contributing to the stabilisation of eastern DRC, in support of the Stabilisation and Reconstruction (here in after referred to as STAREC) programme of eastern DRC of the Government. Supported by donors, the strategy is managed by a Stabilisation Support Unit (SSU) established within MONUSCO, in direct collaboration with the STAREC team. The I4S program is currently in its third phase 2018-2022, after the first phase 2008-2012 and the second phase 2013-2017. Its structure is organised around (i) an integrated strategy comprising five programmatic pillars; (i) a financing mechanism (Coherence Fund for Stabilisation); (iii) an external project alignment mechanism, upstream and downstream; and (iv) close communication with donors and national partners.

The I4S is a strategy that tackles the different structural and underlying causes of conflict through both a Bottom-up approach, through building the capacity of civil society to hold the state accountable, and an approach Top-down, by supporting the Congolese State to provide services to the people and to strengthen its authority. It is at the heart of the Nexus in areas where humanitarian needs and development constraints are linked to violence.

The I4S currently covers three provinces (Ituri, North and South Kivu) around 
13 priority areas. Six zones are currently operational (2 in Ituri, 2 in North Kivu, and 2 in South Kivu). A second programming cycle to extend the operationalisation to 12 zones is planned for the period 2019-2022. At the programmatic level, it comprises 5 pillars: (i) democratic dialogue; (ii) security; (iii) restoration of the authority of the State; (iv) reintegration and socio-economic revival; and (v) women, peace and security.

\section{The Humanitarian Fund (OCHA)}

Managed by UNDP and OCHA, the Humanitarian Fund was created in 2006 at the initiative of donors to support humanitarian reform in the DRC. It was placed under the authority of the Humanitarian Coordinator (here in after referred as HC). It funds the humanitarian projects identified in the Humanitarian Response Plans. These projects are implemented by NGOs and UN agencies. The Humanitarian Fund received approximately US \$ 968 million from 12 donors between 2006 and 2016, which helped support nearly 7 million people through 1,316 projects. The projects and activities funded by the Humanitarian Fund cover a wide range of sectors and areas: nutrition, protection, health, food security, shelter, logistics, education, hygiene and sanitation, water, etc.(OCHA, 2016).

Emergency solutions provided by humanitarian actors over the last decade have contributed significantly to the existential needs of the affected population, particularly in the east of the country, but have not been sustainable. The need to better articulate and coordinate humanitarian, development and peace interventions would ensure the sustainability of results. The Nexus approach addresses this concern.

\section{UNDP's Interventions for Sustaining Peace in DRC as Part of Its Programmatic Steering Wheel}

At the heart of UNDP's missions are crisis prevention, the fight against poverty and inequality, resilience, sustainable resource management, and sustainable human development, all of which help to consolidate peace and reduce vulnerabilities. 
Following its 2013-2017 Strategic Plan, which has been extended to date, UNDP is working on two priority programmatic axes to address the challenges of peace and development. In the first, dealing with Peacebuilding and Strengthening Democracy, UNDP provides support to the electoral process, justice and security reform, the court of auditors, parliamentary institutions, local governance, and territorial decentralisation. In the second, on Inclusive Growth and Sustainable Development, UNDP provides technical and financial support for the development of SDG-driven development planning tools, community resilience, sustainable resource management, and the fight against climate change. The implementation of these priorities follows three guiding principles: to allow the transition from humanitarian assistance to the consolidation of peace and the strengthening of the rule of law in the long term which is UNDP's comparative advantage for the operationalisation of Nexus; ensure a better spatial and sectoral balance in programming; and obligation of results in the medium and long term(UNDP DRC, 2013, p.4).

Earlier this year, in order to address the issue of fragility, UNDP developed a new approach to intervention in crisis-affected provinces and areas, consisting of structured substantive and comprehensive support as follows; (1) Upstream and (2) Downstream.

Upstream, a comprehensive and integrated package of actions including, is formulation of a SDG-driven provincial development plan, empowerment, M\&E development, support for resource mobilisation, the coordination of aid, all in connection with the Nexus humanitarian, development and peace. The aim is to help the province put in place a development framework structured around the SDGs that can address the challenges of peace and development and channel humanitarian dividends towards sustainable solutions. With the ultimate objective, to help the provinces build their own public policy leadership and create an effective decision-making framework that enables them to ensure the transformation and resilience of their provinces5).

5) Notes prepared by the UNDP DRC Country Office in 2018 and shared with all stakeholders to feed a first reflection on the Nexus: (1) Converge humanitarian assistance in the DRC towards stabilization; (2) project to support the formulation of SDG-focused provincial development plans (UNDP DRC, 2018). 
Downstream is a series of interventions focused on the restoration of state authority and the strengthening of its capacity to deliver basic public services for the consolidation of peace, security and good governance; community governance and capacity building for local actors, especially women and youth, as a foundation for restoring the social contract and the rule of law; stabilisation of livelihoods and access to opportunities in return areas6).

6) UNDP DRC (2018). 


\section{Operationalisation of Nexus: A Coordinated Approach to Effective Addressing Humanitarian, Peace and Sustainable Development Issues in Post-Conflict Areas7)}

1. Rational of an Integrated Approach to Nexus-based Interventions in Post-Conflict Areas

The need to improve cooperation between humanitarian and development actors has been recognised within the UN for a few years now. The adoption in 2006 of the "Delivering as One" framework was a first step to engage development actors in cooperating with humanitarians. For their part, humanitarians were called upon to strengthen collective action in 2005 with the adoption of the Cluster approach of the Inter-Agency Standing Committee. In this structuring, we will remember that two contradictory dynamics emerged around the concept of "Early Recovery" and its dedicated cluster. Indeed, this cluster had to promote both the emergency-development link in all the specific clusters (health, water, etc.) and set up specific activities that could promote this link (work with state institutions, demining, etc.).

For a clear understanding of the history on this link, one can refer to the study "The Continuum of Humanitarian Crises Management: Multiple Approaches and the Convergence Challenge (Gómez and Kawaguchi, 2016).” This questions the response to humanitarian crises and compares different approaches to the emergencydevelopment nexus, building on work on disaster risk reduction and peacebuilding. While describing its advantages and disadvantages, the authors present a model of activities based on a simple and common understanding of the concept to which all actors can come together.

7) This chapter is based on following list of documents: DRC's UNDP Portfolio 2018 (2018); Dag Hammarskiöld Foundation and the Multi-Partner Trust Fund Office (2018); World Bank (2015); World Bank (2018); and Manuel Opérationnel du Fonds Humanitaire en RDC. See references for additional information. 
In May 2016, the World Humanitarian Summit called for a change in the management, planning and implementation of humanitarian action. In its report "One humanity, shared responsibilities," ahead of the summit, the UN Secretary-General launched a global appeal to "change people's lives: moving from providing aid to humanitarian needs. He insisted that the 2030 SDGs should not leave anyone behind and refer to the establishment of a common framework between humanitarian and development actors to ensure maximum security, dignity and ability to thrive (UNSG, 2017).

The Commitment to Act signed at the 2016 World Humanitarian Summit calls on the international community to "New Way of Working (here in after referred to as NWOW)" to achieve a "Humanitarian-Development Nexus" where the convergence between the two pillars is around "collective results." The peace dimension was later incorporated into this approach, which, in the case of the DRC, seems very relevant. The NWOW approach aims to bridge the gap between humanitarian aid and development assistance, and in particular addressing the needs of those most affected by humanitarian emergencies through a more comprehensive and complementary approach (ICVA, 2017).

The NWOW therefore responds to the need for humanitarian and development actors to align with common and sustainable collective results that address the sources of conflict, strengthen the resilience of affected populations, and project a better trajectory towards sustainable development. This approach requires actors working in the humanitarian / stabilisation / development continuum to collaborate and plan a coordinated multi-year response framework that maximises overall results and minimises the risk of backtracking. In the same perspective, it makes it possible to increase the coherence and effectiveness of aid deployment.

The effectiveness of the NWOW approach, operationalised by the Nexus, is corroborated by the theory of cooperative games. When all actors agree to work together and work in a coordinated and synergistic framework, the coordination of interventions and the economies of scale that it allows will lead to efficiency and effectiveness gains, leading to optimal balance. In the context of the Nexus, 
efficiency and effectiveness gains from coordination will transform short-term humanitarian dividends into recovery and resilience, thus enabling sustainable economic and social transformation, in a medium-term and long-term perspective (3 to 5 years).

So, by and large, without being exhaustive, the Nexus approach allows:

- Better articulate humanitarian aid and development assistance so as to put the former in a sustainable perspective;

- Reduce long-term humanitarian needs by making the best use of existing resources and capacities;

- Improve the coordination of actions on the continuum with a view to generating efficiencies and efficiencies to achieve improved and high collective; and

- Boost partnerships, especially with the private sector, local actors, and multilateral banks, which can provide additional capacity and resources to achieve collective and measurable results for people and communities emerging from crises (ICVA, 2017; OCHA, 2018).

\section{Approach and Methods of Operationalisation of the Nexus}

Conceptually, the operationalisation of the nexus is based on the analytical framework and the approach developed by the NWOW. This approach describes how Nexus actors and their national counterparts can effectively coordinate their interventions, to achieve improved collective outcomes that reduce the long-term needs, risks and vulnerabilities of affected populations.

The NWOW Analytical Framework calls for committed actors on the humanitarian, development and peace continuum to agree on at least three important commitments and to design effective practical modalities for successful implementation of the 
Nexus. These commitments include: ( i ) joint multi-year SDG-based programming with a clear roadmap to contribute to the long-term resilience and development of affected communities; (ii) tangible collective results in reducing needs, vulnerability and risks; and (iii) collaboration based on comparative advantages in the different areas of intervention. In practical terms, these commitments will be articulated around four practical actions: conducting a joint analysis of the situation; develop a joint and coordinated planning and programming process with M\&E indicators; put in place effective coordination; and design effective financing modalities for multi-stakeholder and multisectoral activities.

\section{Operationalisation of the Nexus in the Context of DRC}

Under the coordination of Deputy Special Representative of the Secretary General (here in after referred to as DSRSG), Resident Coordinator (RC), HC, and UNDP Resident Representative (UNDP RR) in the DRC, a committee composed of UNDP, OCHA, United Nations International Children's Emergency Fund (here in after referred to as UNICEF), the World Bank, the office of DSRSG and Stabilisation Support Unit (SSU) of MONUSCO has been put in place for the operationalisation of the Nexus in the DRC. At this stage, a strategic note for operationalisation of the Nexus with some of concrete proposals called Nexus Pilots has been elaborated. In the note, as a first step, it is proposed to operationalise the Nexus through the establishment of NWOW elements within a limited number of Nexus pilots to ensure greater complementarity and coherence between humanitarian efforts, development and peace. In practical terms, the Nexus will first be implemented provincially and locally, and not nationally, to test the effectiveness of the approach. Its operationalisation would be done through Nexus Pilots articulated around the geographical zones out of crises (provinces, territories, grouping, ...) or key themes (displacement of populations, recovery, resilience, stabilisation, etc.) (UNDP Nexus Core Team and OCHA DRC, 2018). 


\section{The Implementation Phasing of the Nexus in an Identified Nexus Driver Would} Then Decline

제I 장

the framework of the Nexus. It is important to involve donors at this stage to ensure funding; (2) Conducting a joint and holistic needs analysis, which will consist of assessing the needs, risks and capacities needed to address the root and structural causes of the problem, as well as the risks and vulnerabilities of the communities and / or affected areas; (3) Conduct joint planning / programming / budgeting, based on data collected during the joint analysis; (4) Definition of the expected collective results, for a period of 3 to 5 years, with intermediate targets to be reached; (5) Establishment of an effective coordination mechanism including all Nexus actors (Humanitarian-Development-Peace) and local authorities (and possibly beneficiaries); (6) Establishment of a predictable, flexible and multi-year funding mechanism over a minimum period of 3 years, preferably 5 years, to ensure sustainable collective results.

\section{Nexus Pilots Identified in the DRC}

The following is Nexus Pilots identified in the DPR; (i) Grand Kasai (Kasai Central, Kasai, Kasai Oriental, Lomami, Sankuru) around a global response on issues of security, IDPs, agriculture, nutrition, education, health, reproductive health, human rights, GBV, etc; (ii) Ituri around issues of IDPs, refugees, democratic dialogue, local governance, etc .; (iii) North and South Kivu around issues of stabilisation, recovery, rule of law, human rights, GBV, local governance, community recovery, and; (iv) Tanganyika around Pygmy and Bantu conflicts; (v) Beni around a comprehensive and sustainable response to Ebola Virus Disease; (vi) Provinces of Equateur in Mbandaka around a global and sustainable response to the "Ebola Virus Disease": 
early warning and monitoring system, strengthening of health structures, agriculture, etc.

\section{Axes of Possible Thematic Interventions of the Nexus}

The focus could be on several themes, including (i) health with a focus on epidemics; (ii) food insecurity and malnutrition; (iii) access to basic social services for the most vulnerable (drinking water, electricity, health, and education); (iv) long-term IDPs; (v) reduction of violence; etc.

\section{UNDP Strategic Positioning in the Nexus}

UNDP is a key player in the development process, working on a broad spectrum of the Nexus, from stabilisation, recovery, development, to peacebuilding. It also plays a unifying role (Integrator) in the implementation of the 2030 Agenda for Sustainable Development. Based on its comparative advantages and its experience gained, it is strategically positioned on the various niches below. (i) Stabilisation (North Kivu, South Kivu and Ituri) with a focus on the rule of law, local governance, political dialogue, security, justice, GBV, etc.; (ii) recovery (Grand Kasai, North and South Kivu); (iii) development, with a focus on the SDGs; (iv) peace and sustainable solutions, including on issues of refugees, IDPs, etc. 


\section{Opportunities and Recommendations for a Stronger Partnership with Donors, Mainly Bilateral Donors, including KOICA, for a Sustaining Peace in the DRC}

existing partnerships. Korea International Cooperation Agency (here in after referred to as KOICA), as a key bilateral partner, could be mobilised for the stabilisation components (rule of law, local governance, political dialogue, security, justice, GBV, etc.), peace (displaced, refugees, pygmy / bantu conflicts in Tanganyika, etc.) and Recovery of affected communities (improvement of economic opportunities). As a concrete example to clearly see how the Nexus can be operationalised in the field, a humanitarian intervention for food crises in the Grand Kasai provinces is being implemented by Food and Agriculture Organization (FAO), UNICEF, and World Food Programme (WFP) funded by the World Bank in the context of ongoing and post-conflict situations. To gradually transform the dividends of humanitarian action into sustainable recovery, capacity for resilience and development opportunities, KOICA-UNDP Nexus Pilot programme, for example, can be jointly developed to work in the region by conducting a joint analysis of the situation, social cohesion, institution building, support for long-term joint planning support at the provincial level. The DRC government has recently launched the National Strategy for Sustainable Solutions for the IDPs and returnees which is another relevant example directly liked to the Nexus where the partnership can be built to support the strategy for the IDPs and returnees in the eastern provinces such as Tanganyika and North Kivu. 


\section{Vl. Conclusion}

The expected results of Nexus and NWOW engagement will be to ensure that humanitarian, development and peace actors establish the strategic and programmatic foundations for setting common goals to ensure greater coherence and coherence. Increased convergence of interventions. The results of the Nexus will be long-term and based on the implementation of the NWOW elements and the objectives of the "collective results." The mobilisation of financing in a context of political uncertainties will be one of the key success factors of the Nexus in the DRC. Bilateral partner like KOICA can play a major role in this process. 


\section{〈References〉}

Aperçu de la Crise en. 2018. "RD Congo: Plan de Réponse Humanitaire 2017 (Mise à jour pour 2018)." Kinshasa: United Nations Office for the Coordination of Humanitarian Affairs, available at https://www.human itarianresponse.info/en/operations/democratic-republic-congo/document/rdcongo-plan-de-r\%C3\%A9ponse-humanitaire-2017-mise-\%C3\%A0-jour.

Agenda for Humanity. 2018. "Multi-Stakeholder Regional Workshop on the New Way of Working, West and Central Africa," available at https://www. agendaforhumanity.org/sites/default/files/resources/2018/Aug/NWOW-W orkshop-Report-20180713.pdf.

Dag Hammarskjöld Foundation and the Multi-Partner Trust Fund Office. 2018. "Financing the UN Development System: Opening Doors." Uppsala: Dag Hammarskjöld Foundation, available at https://www.daghammarskjold. se/wp-content/uploads/2018/09/financial-instr-report-2018-interactive-p df_pj.pdf.

Expériences de mise en place de la Nouvelle Manière de Travailler au Soudan, la Somalie, et le Bassin du Lac Tchad.

Gomez, Oscar A., and Chigumi Kanaguchi. 2016. "The Continuum of Humanitarian Crises Management: Multiple Approaches and the Convergence Challenge." Japan International Cooperation Agency (JICA) Working Paper, no.136, available at https://www.jica.go.jp/jica-ri/publication/workingpaper/wp_ 136.html.

ICVA. 2017. "The New Way of Working Examined: An ICVA Briefing Paper." Geneva: A Global NGO Network for Principled and Effective Humanitarian Action, available at https://www.icvanetwork.org/system/files/versions/ ICVA_NWoW_Briefing_paper.pdf.

ISSSS. 2013. "International Security and Stabilisation Support Strategy 2013-2017.” Kinshasa: United Nations Organization Stabilization Mission in the Democratic Republic of the Congo (MONUSCO), available at http://www.unpbf.org/wp-content/uploads/ISSSS-2013-2017-StrategicFramework-FINAL_EN.pdf. 
OCHA. 2017. "New Way of Working (NWOW)." New York: Office for the Coordination of Humanitarian Affairs (OCHA), Policy Development and Studies Branch (PDSB), available at https://www.unocha.org/sites/unocha/ files/NWOW\%20Booklet\%20low\%20res.002_0.pdf.

. 2017. "République démocratique du Congo: Aperçu des besoins humanitaires." Kinsha: UN Office for the Coordination of Humanitarian Affairs, available at https://reliefweb.int/report/democratic-republic-congo/ $\mathrm{r}$-publique- $\mathrm{d}$-mocratique-du-congo-aper- $\mathrm{u}$-des-besoins-humanitaires -0 2018. "COLLECTIVE OUTCOMES: Operationalizing the New Way of Working." UN Office for the Coordination of Humanitarian Affairs is a United Nations, available at https://www.agendaforhumanity.org/sites/ default/files/resources/2018/Apr/OCHA\%20Collective\%20Outcomes\%20A pril\%202018.pdf.

PLAN-CADRE DES NATIONS UNIES POUR L'ASSISTANCE AU DÉVELOPPEMENT - UNDAF 2013-2017,” available at http://cd.one.un.org/ content/dam/unct/rdcongo/docs/UNCT-CD-UNDAF.pdf.

UNDP DRC. 2013. “Country Program Document 2013-2017.” Kinshasa: United

Nations Development Programme, Democratic Republic of Congo. . 2018. Notes on the Nexus, prepared shared by UNDP Country Office Country Office with stakeholders in 2018.

UNDP Nexus Core Team and OCHA DRC. 2018. "Draft concept Note on Operationalization of the HDP Nexus in the DRC" elaborated on October 30, 2018.

UNSG. 2017. “UN Secretary-General Report: Repositioning UNS for Development for the Implementation of the 2030 Agenda: Our Promise of a Life with Dignity, Prosperity and Peace on a Healthy Planet" adopted on 20 December 2017 by the United Nations General Assembly. A/72/684-E/2018/7.

UNSSC. “Le Programme de développement durable à l'horizon 2030.” Bonn: United Nations System Staff College, available at https:/www.unssc.org/ sites/unssc.org/files/2030_agenda_for_sustainable _ development_kcsd_primer_fr.pdf. 
WHS HDAG. "thinkpiece - Better Humanitarian-Development Cooperation for Sustainable Results on the Ground," available at https:/cic.nyu.edu/ publications/after-world-humanitarian-summit-better-humanitarian-dev elopment-cooperation-sustainable.

World Bank. 2015. "FROM BILLIONS TO TRILLIONS: MDB Contributions to Financing for Development.” World Bank Report, July 2015. Washington D.C.: World Bank, available at http://documents.worldbank.org/curated/ en/602761467999349576/pdf/98023-BR-SecM2015-0233-IDA-SecM2015-0 147-IFC-SecM2015-0105-MIGA-SecM2015-0061-Box391499B-OUO-9.pdf. . 2017. "Country Assistance Strategy for DRC, World Bank, 2013-2016." Washington D.C.: World Bank, available at http://documents. worldbank.org/curated/en/664211468246896400/Congo-Democratic-Republ ic-of-Country-Assistance-Strategy-for-the-period-FY13-FY16. 2018. "World Bank Group Engagement in the Democratic Republic of the Congo" posted on World Bank website on May 16, 2018, available at https://www.worldbank.org/en/country/drc/overview\#2.

World Humanitarian Summit. 2016. “Commitment for Action” posted on World Humanitarian Summit website on 23 May, 2016, available at https:// interagencystandingcommittee.org/system/files/whs_commitment_to_acti on_-_transcending_humanitarian-development_divides_0.pdf. 